\title{
ALLERGIC CONJUNCTIVITIS - DOES URBANIZATION INFLUENCE?
}

Purvi Raj Bhagat ${ }^{1}$, Rupal B Bhatt ${ }^{2}$, Raj G Bhagat ${ }^{3}$, Kalyani Deshpande ${ }^{4}$

\section{HOW TO CITE THIS ARTICLE:}

Purvi Raj Bhagat, Rupal B Bhatt, Raj G Bhagat, Kalyani Deshpande. "Allergic conjunctivitis - does urbanization influence?". Journal of Evolution of Medical and Dental Sciences 2013; Vol2, Issue 38, September 23; Page: 7280-7287.

ABSTRACT: An allergy is a hypersensitivity disorder of the immune system and an environmental disease, which occurs due to interaction between host \& environmental (natural \& human origin) factors. Over the last few decades, allergic diseases have increased worldwide. An association has been found with just about everything - poverty, global warming, pollution, new airtight houses, obesity, use of antibiotics, race, intestinal flora, family size, daycare centers, intestinal parasites. The existence of urban allergy syndrome as a distinct, clinically relevant entity now needs to be established. As it has a great impact on the person's quality of life, it is of utmost importance to understand the mechanism, the role of environmental modulation and the optimal modalities available for its treatment.

KEY WORDS: urban, allergy, conjunctivitis, pollution, environment.

INTRODUCTION: An allergy is a hypersensitivity disorder of the immune system and an environmental disease, which occurs due to interaction between host \& environmental (natural \& human origin) factors. The term allergy (allos - altered state, ergon - reaction) was first coined by the Austrian physician Clemens von Pirquet. [1] Allergic reactions occur when a person's immune system reacts to normally harmless substances in the environment. These reactions are acquired, predictable and rapid. The exciting substance that causes the reaction is called an allergen.

Over the last few decades, allergic diseases have increased worldwide and the prevalence rate is as high as $20 \%$. [2] Pollen, the most common allergen has existed since long, then why is there a recent skyrocketing in the incidence of allergy? [3] Also, why is urban allergy on the rise when pollens are found more in rural areas? Since allergens have existed all along, there are surely other aggravating factors to justify the current prevalence.

There are conditions which are an overlap of dry eye, allergy and a toxic irritative type of conjunctivitis. There is also a definite subset of individuals with chronic conjunctivitis symptoms who does not suffer from allergy or dry eye. [4] This subset has been named "urban allergy syndrome" or pollution keratoconjunctivitis. Other names coined for the condition are Perennial chronic conjunctivitis [5], generic conjunctival hyperreactivity to nonspecific stimuli ${ }^{[4]}$,vasomotor conjunctivitis[6], pseudo-allergic conjunctivitis, nonspecific conjunctival hyperreactivity and discomfort eye syndrome, ${ }^{[7]}$ perennial non-allergic conjunctivitis ${ }^{[8]}$.

Recent studies have shown that many modern day environmental factors, most notably, air pollution, can trigger, catalyze and amplify allergic reactions. ${ }^{[9]}$ Allergens are upto 50 times more likely to generate an allergic response in the presence of pollution. Air pollution also directly irritates the eye and unlike other conditions affected by air pollution, for example, asthma, the effect on the eye is immediate. ${ }^{[10]}$ Although this makes sense, few studies have been published on the topic. Allergies have long crossed socio-economic barriers and because they have a great impact on the 


\section{REVIEW ARTICLE}

person's quality of life, it is of utmost importance to understand the mechanism of allergy, the role of environmental modulation and the optimal modalities available for treatment.

\section{Pathogenesis:}

Three probable mechanisms explaining the pathogenesis of allergy have been suggested:

- Immunotoxicity - Pollutants act as co-factors with the allergen and increase the immune response to the allergen.

- Pro-inflammatory effect - Pollution creates an inflammatory reaction thereby facilitating allergy.

- Increased allergenicity - Pollution modifies the allergen itself and augments the allergic response.

Effect of Pollens: Pollens are the most common allergens. Pollens with organic matter adherent to it secrete significantly large amount of pro-inflammatory substances compared to pollens freshly collected from grass.[11] A marked difference has been found between pollen found near road side and pollen found in rural meadows,[12] explaining the increase of allergies in urban areas even though pollens are present more in rural areas. Pollen sensitization is increased by exposure to pollutants from 24 - 48 hours. Pollutants make the surface of the exine more fragile, triggering a mucosal reaction and making them more exposed to pollen allergens.[13]

Our eyes can be compared to two huge pollen collecting dishes \& are the perfect entryway for allergens. Studies have shown that if an allergen is put in the eye, not only do $80 \%$ of patients get eye allergies, but they also get nasal allergies. But if an allergen is put up the nose, only nasal allergy develops and not ocular allergy. [3] Sensitized mice develop symptoms of rhino conjunctivitis when exposed to common allergenic pollens, and when exposed to diesel exhaust with pollen, the allergic symptoms are even worse. ${ }^{[14]}$ Diesel exhaust accumulates on pollen grains, alters their morphology and causes them to release their protein constituents. Thus, urbanites are in more contact with the allergenic properties of pollen than their rural counterparts ${ }^{[1,15]}$ and polluted pollen is more effective than non polluted pollen in inducing allergic reactions.[16]Rising carbon dioxide emissions (from cars, trucks and factories) are actually causing plants to boost pollen production. Carbon dioxide in the atmosphere is expected to double by the end of this century and such an increase would lead to an estimated $61 \%$ more pollen release from ragweed. [17]

Such exposure has led to the diagnosis of a new allergy-like conjunctivitis, the "urban eye allergy syndrome" that is not directly caused by allergy, but largely by pollution. ${ }^{[18]}$

Effect of Tobacco: Tobacco is also an important indoor pollutant. Environmental tobacco smoke (ETS) triggers IgE production, the principal anti-allergy antibody. Multiple epidemiological studies have shown that maternal smoking is a major risk factor for allergic disease in children. ${ }^{[19]}$ Passive smoking during pregnancy or lactation has been found to be a risk factor for the development of vernal keratoconjunctivitis, Obstructive respiratory disease $\&$ atopic eczema in the offspring. Smoke exacerbates both, allergy and asthma. In Western world, daily exposure of children to ETS is as high as $40 \%$ to $60 \%$.[20] Cigarette smoke is known to be full of free radicals which oxidize the lipid layer of the tear film, speeding its breakdown.[1,21] Several studies have now established that air pollution, including diesel exhaust, has similar effects on the tear-film barrier. $[1,22,23,24]$ A diminished tear film 
as a result of these factors can lead to dry-eye symptoms, opening the eye to the pollution-ridden pollen and allowing the allergic state to be maintained.

Effect of Air Pollution: Several epidemiological studies have demonstrated an association between air pollution and an increased rate of asthma and allergic conjunctivitis. Many traffic related air pollutants increase allergic reactions by increased sensitization as well as an increased response of the sensitized person.

Air pollution can be divided into two types -

Type 1- High $\mathrm{SO}_{2}$ level \& large dust particles

Type 2 - Fine \& ultra fine particles, $\mathrm{NO}_{2}$, Ozone, Tobacco smoke, Diesel Exhaust Particles [25]

Type 1 pollution rarely produces allergy but is linked to viral \& bacterial inflammation. Type 2 air pollution is modern society air pollution \& increases the prevalence of allergic reactions. Common air pollutants like ozone, $\mathrm{SO}_{2}$ and $\mathrm{NO}_{2}$ probably act more as irritants than as promoters of sensitization. [26] Control studies show that persons develop allergic reaction only if they have been exposed to Type-2 pollutants like tobacco smoke or diesel exhaust particles. These pollutants directly injure the mucous membrane \& increase the permeability of the epithelium leading to release of inflammatory mediators. Persons who are genetically susceptible to allergic rhino conjunctivitis release significantly more inflammatory mediators compared to non-atopic individuals. Pollution also damages the body's defenses allowing greater access for allergens to invade. This increases the opportunity of exposure to environmental allergens and jumpstarts the process of allergic sensitization. [3, 27] Air pollutants also create low-level ozone which results in oxidative stress on the conjunctival epithelium. This, in turn, potentially diminishes the protection provided by the tear film barrier making it easier for allergens to penetrate into the eye, exacerbating the severity of allergy. Thus, what would have been an occasional and mild complaint becomes a chronic, prolonged intense reaction. Suspended particles in the air are divided into 3 categories: coarse $(2.5-10 \mu \mathrm{m})$, fine $(<2.5 \mu \mathrm{m})$ and ultrafine $(<0.1 \mu \mathrm{m})$. Diesel Exhaust Particles (DEPs) fall under fine \& ultrafine categories and are one of the major air pollutants in urban districts. ${ }^{[28]}$ They increase the histamine release from allergen activated mast cells \& lead to severe allergic conjunctivitis. These ultra fine pollutants generate superoxides which lead to a low level inflammatory process on the ocular surface causing irritation. ${ }^{29]}$ DEPs also boost IgE production.

Another currently accepted explanation for how pollutants cause symptoms is the mucosal adjuvant hypothesis. ${ }^{[4,30]}$ According to the hypothesis, humans are not allergic to pollutants. Instead, airborne pollutants act as mucosal adjuvants - they interact with innate and adaptive immune cells, skew the immune response to antigens to a T-helper2-like phenotype, and, in genetically predisposed (atopic) individuals, increase expression of both allergic response and allergic disease. ${ }^{[4]}$ Some studies demonstrate a hierarchical response to DEPs : low exposure leads to the formation of reactive oxygen species, activating anti-oxidant response elements. ${ }^{[31]}$ This may explain why some patients do not develop symptoms and some do. Genetically susceptible people lacking free radical scavenging enzymes (egg. glutathione transferase enzyme) are more likely to suffer due to super oxide induced damage. Their conjunctiva becomes more porous and more susceptible to pollens and frequent attacks of allergic conjunctivitis. Sunlight also reacts with diesel exhaustproduced hydrocarbons and nitrous oxide to produce low-level ozone, which causes oxidative 
stress. Research has also demonstrated that pollen grains contain oxidases that become reactive when hydrated. [1]

According to Caparas, [4] the association between ambient air pollution and ocular symptoms is well documented. Individuals living in areas with high levels of air pollution complain of ocular symptoms more frequently. An increase in ambient PM10 (particulate matter measuring less than $10 \mu$ in diameter) of about $10 \mu \mathrm{g} / \mathrm{m}^{3}$ has been associated with increased clinic visits for symptoms of conjunctivitis. National Ambient Air Quality Standards (NAAQS) set by the US Environmental Protection Agency (EPA) is about $90 \mu \mathrm{g} / \mathrm{m}^{3}$ of total suspended particles (TSPs). ${ }^{[4]}$

Research shows that about $80 \%$ to $90 \%$ of people who have allergic rhinitis also have ocular allergic complaints. Another study has shown that allergic conjunctivitis symptoms are at least as severe as rhinitis symptoms in \approximately $70 \%$ of people with allergic rhinitis. More than half of nasal allergy sufferers say that their red, itching eyes (53\%), headache (51\%) and watering eyes (51\%) are extremely or moderately bothersome. Furthermore, red, itching eyes are the most bothersome symptom of $10 \%$ of nasal allergy sufferers, and watering eyes are the most bothersome symptom of $5 \%$ of nasal allergy sufferers. [3]

Effect of lifestyle \& environment: The role of the environment is equally important as it is what turns the various genetic tendencies into frustrating afflictions. [1,25]Changes in housing have also produced an important impact. Increasing emphasis on energy conservation has resulted in sealing of homes with tightly fitted windows and doors resulting into poor air exchange. Increased use of central heating and air conditioning systems, as well as soft furnishings and carpets associated with improved socioeconomic status improve the habitat for dust mites. [32] Children living closer than 50 meters to a busy street had the highest probability of getting allergic symptoms, compared to children living further away. ${ }^{[3,33]}$ Apartment living creates a physical gap between humans and the soil. Lower standards of living, use of day nurseries from an early age probably promotes infection and accounts for lower incidence of allergy in certain communities. A particularly plausible hypothesis is the 'lazy immune or hygiene hypothesis' i.e. asthma and allergy are epidemics resulting from the absence of infection. Reduced exposure of small children to bacterial and infectious agents, by reducing the TH1 like cytokine influence on the development of the immune response, at a time when infants are exposed to high concentrations of allergens, provides an attractive hypothesis for explaining the world-wide trends. Godfrey investigated the occurrence of allergy and asthma in Gambian school children and showed their association with urban dwellers, higher socioeconomic status and lower total circulating IgE levels. ${ }^{[34]}$ He suggested that in the rural setting, parasite infection was protective against the development of allergy and asthma.

Thus, there seem to be two basic seemingly opposing causes: the dirty cause and the clean cause. The dirty cause (or pollution hypothesis) suggests that increased pollution in our environment has overburdened and hypersensitized our immune systems. The clean cause (or hygiene hypothesis) suggests that we have made our modern household environment so clean that our bodies overreact to otherwise harmless microbes and pathogens. This hygiene hypothesis has plenty of support. It started with a study that found that allergic rhinitis and eczema are less common in children from larger families who presumably expose each other to more infectious agents than in families with only one child. [3] Population-based surveys in the developed world also indicate that the more affluent sections of the community have the highest prevalence of allergic 
sensitization and associated diseases. But the hygiene hypothesis also has some loopholes. Evidence shows that the inner-city poor, who are exposed to greater allergens and microbes, and should presumably benefit from the hygiene hypothesis, actually have higher rates of allergies. Also, viral infections prevent the development of allergic disease. But, the influenza virus now appears to enhance the development of asthma and allergic responses. ${ }^{[3]}$ Another curious anomaly is that the rates of allergic rhinitis and asthma have increased through the 20th century; they appear to have reached a peak among children in the early 1990s and may now be on a decline. [3] The hygiene hypothesis does not explain such an anomaly since concurrent environmental exposure has not declined. Thus, unfortunately, neither of the hypothesis provides all the answers.

Both ocular and respiratory allergies are thought to be closely related and an association has been found with just about everything - poverty, global warming, pollution [15] new airtight houses, obesity, use of antibiotics, race, intestinal flora, family size, daycare centers, intestinal parasites, etc.[1]Yet no single all-encompassing dogma has arisen to explain the increasing prevalence of allergies.

Role of genetics: If one parent suffers from allergy, the child is $40 \%$ more likely to have allergy; if both parents have allergy, their children are $75 \%$ more likely to have allergy, according to the American College of Allergy, Asthma \& Immunology. [3] A threshold exists at which genetically predisposed individuals show allergic symptoms to airborne particulates - a threshold that varies from person to person and that is dramatically lower in the presence of pollution. ${ }^{[1,35]}$

Prevention and treatment: Humidifiers, air purifiers and pointing fans and car vents away from eyes maybe helpful in minimizing symptoms. Avoiding prolonged outdoor activities in the peak pollen seasons is helpful but maybe impractical.

The key to protection from harmful effects of pollutants is to improve the cytoprotective response of body through activation of an antioxidant which works by neutralizing free radicals. They donate their own electron to super oxidize \& thus end the electron steeling chain. [31] Findings also support the notion that allergy sufferers who carry the particular genes may experience lighter symptoms if they take antioxidant vitamins that help the body cope up with the pollutants. ${ }^{[36]}$ There are many substances available in nature which are proving to be effective antioxidants eg. quercetine, myricetine. They are plant products and are systemically effective. However, topical therapy should be the most effective approach for treating ocular allergy. Antioxidants like quercetine, if can be dispensed in the form of eye drops can do good to control urban allergy.

There is a large armamentarium of anti-allergy drugs available - antihistamines, mast cell stabilizers and antihistaminic \& mast cell stabilizer combinations. eg., Olopatidine, Epinastine, Azelastine, Ketotifen. The combination products are the most effective. They inhibit histamine binding to the receptors in the conjunctiva and also prevent conjunctival mast cells from degranulating and releasing more histamine and other pro-inflammatory mediators. Ironically, systemic antihistaminics can cause clinically significant dry eye symptoms. [1, 37] Topical antihistamine / mast cell stabilizers such as Olopatadine $0.1 \%$ have high $\mathrm{H} 1$ receptor affinity and selectivity. They therefore do not affect the tear-film stability and do not dry the ocular surface. [1] So Olopatadine is a safer option in patients of allergic conjunctivitis who also have dry eye. However, no topical allergic conjunctivitis medication builds up the tear film. It is therefore beneficial to treat 
patients of eye allergies not only with antihistamine / mast cell stabilizers, but also with tear substitutes. Although dry eye is separate from allergy, it is also related to pollution. [1, 24] Immunomodulators like Aspirin, glucocorticoids, non-acetylated salicylates also modify allergic response and can be tried.

Though genetics has a definite role in urban allergy, there is little scope for modifying this factor, but behavior modification can definitely be attempted. Strategies can be developed to reduce diesel emissions further, especially in populations susceptible because of environment or underlying respiratory disease. Even with multiple treatment modalities surfacing for urban allergy syndrome, prevention is still the best cure!

CONCLUSION: To conclude, the existence of urban allergy syndrome as a distinct, clinically relevant entity now needs to be established. An exceptionally complex interplay of factors will have to be considered in proving a causal relationship between air pollution and a non-allergic, non-dry eye type of conjunctivitis. The people most affected are the genetically susceptible, elderly, with preexisting chronic disease, with diabetes mellitus ( all of which are associated with oxidative stress \& inflammation ) and those with Dry eye, since the corneal surface is at high risk of oxidative damage by environmental pollution due to lack of tear anti-oxidants.

\section{REFERENCES:}

1. Mark B. Abelson, Lauren Lilyestrom: Paving the Pastures: Urban Life and Allergy: The impact of our environment on our susceptibility to allergic reactions : Review of ophthalmology : 2/15/2007

2. European Allergy White Paper : Allergic diseases as a Public Health Problem Abstract - The UCB Institute of Allergy, 2004

3. John Murphy: Why Are Allergies on the Rise? A century ago, allergies were rare : Review of optometry, Vol. no. 145: 08, 8/15/2008

4. Chiles Aedam R. Samaniego : Urban allergy syndrome : Ocular Surface \& Dry Eye : Eye World Asia-Pacific : Vol. 5, No. 3, 2009

5. Leonard Bielory: Vasomotor (perennial chronic) conjunctivitis : Current Opinion in Allergy and Clinical Immunology 2006, $6: 355-360$

6. Sivko MT: Vasomotor conjunctivitis : Oftalmol Zh: 1971, 26 : 306-307

7. Versura P, Profazio V, Cellini M : Eye discomfort and air pollution : Ophthalmologica 1999, 213(2) : 103-9

8. Enberg RN: Perennial nonallergic rhinitis: a retrospective review : Ann Allergy, 1989 Dec, 63(6 Pt 1) : 513-6

9. Ring J, Kramer U, Scgafer T, Behrendt H: Why are allergies increasing ?: Curr Opin Immunol, 2001, $13: 701-08$

10. Chia- Jen Chang, His- Hsien Yang, Chin- An Chang, Hsien- Yang Tsai : Invest Ophthalmol Vis Sci., 2012, 53 (1) : 429-433

11. Behrendt H, Becker WM, Freidrichs KH, Darsaw U, Tomingas R. : Interaction between aeroallergens and airborne particulate matter : Int Arch Allergy Immunol., 1999: 118: 41418 
12. Behrendt H, Tomczok J, Sliwa - Tomczok W, Kasche A, Ebner von Eschenbach C, Becker WM, Ring J. Timothy: Grass Pollen as allergen carrier and initiation of allergic response : Int Arch Allergy Immunol., 1999, 118 : 414-18

13. Peltre G: Inter-relationship between allergenic pollens and air pollution: Allerg Immunol (Paris), 1998 Dec., 30 (10): 324-6.

14. Matsumoto A, Hiramatsu K, Yingji L: Repeated exposure to low dose diesel exhaust after allergen challenge exaggerates asthmatic responses in mice : Clin Immunol., 2006, 121: 227 235.

15. Majd A, Chehregani A, Moin M, Gholami M, Kohno S, Nabe T, M.A. Shariatzade: The effects of air pollution on structures, proteins and allergenicity of pollen grains : Aerobiologia 2004, 20: 111-118.

16. Chehregani A, Majde A, Moin M : Increasing allergy potency of Zinnia pollen grains in polluted areas: Ecotoxicol Environ Saf 2004 June, 58(2) : 267-72

17. Wayne P, Foster S, Connolly J, Bazzaz F, Epstein P: Production of allergenic pollen by ragweed (Ambrosia artemisiifolia L.) is increased in CO2 enriched atmospheres: Ann Allergy Asthma Immunol 2002, March 88(3) : 279-82.

18. Leonardi A, Lanier B : Urban eye allergy syndrome: a new clinical entity? Curr Med Res Opin 2008, June 28

19. Schäfer T, Dirschedl P, Kunz B, Ring J, Uberla K: Smoking during pregnancy and lactation increase the risk of allergy in the offspring : J Amiseal Acad Dermetol. 1997, 36 : 550-56

20. David Diaz Sanchez, Robert Rurnold, Henry Gong : Challenge with environmental tobacco smoke exacerbates allergic airway disease in human beings : Environmental and occupational respiratory disorders Challenge : Aug 6, 2011

21. Altinors D, Akça S, Akova Y, Bilezikçi B, Goto E, Dogru M, Tsubota K : Smoking associated with damage to the lipid layer of the ocular surface : Am J Ophthal 2006, 141 : $6: 1016$

22. Versura P, Profazio V, Cellini M, Torreggiani A, Caramazza R: Eye discomfort and air pollution: Ophthalmologica 1999, 213: 103.

23. Gupta SK, Gupta V, Joshi S, Tandon R: Sub clinically dry eyes in urban Delhi: An impact of air pollution ? : Ophthalmologica 2002, $216: 5: 358-371$

24. Sahai A, Malik P : Dry eye : Prevalence and attributable risk factors in a hospital-based population : Indian J Ophthalmol 2005, $53: 2: 87-91$

25. MB Abelson, L Smith, M Chapin: Ocular allergic disease: mechanisms, sub type, treatment : Ocul surf. 2003, $1: 127-49$

26. Alan Szeftel: Air Pollution and Allergies: A Connection? : Medicine net. com, Dec. 2012

27. Passali D, Lauriello M, Mezzedimi C, Bellussi L: Nasal allergy and atmospheric pollution: Int J Pediatr Otorhinolaryngol 1999, Oct 5, 49 Suppl 1: S 257-60.

28. David Peden, Charles E. Reed, Chapel Hill, NC, Rochester Minn: Environmental and occupational allergies : J Allergy Clin Immun 2010, Vol. 125 No.2

29. Diaz-Sanchez D, Proietti L, Polosa R: Diesel fumes and the rising prevalence of allergy - an urban legend? : Curr Allergy Asthma 2003, 3 : 146-52

30. Saxon A, Diaz-Sanchez D: Air pollution and allergy: you are what you breathe: Nat Immunol. $2005,6: 223-26$ 


\section{REVIEW ARTICLE}

31. Xiao GG, Wang N, Loo J, Nel A: Use of proteomics to demonstrate a hierarchical oxidative stress response to diesel exhaust particle chemicals in a macrophage cell line. J Biol Chem. 2003, 278 (50): 50781-90.

32. Zhang G, Spickett J, Lee A, Rumchev K, Stick S: Household hygiene practices in relation to dampness at home and current wheezing and rhino-conjunctivitis among school age children: Pediatr Allergy Immunol 2005, 16: 587-592.

33. Morgenstern V, Zutavern A, Cyrys J, et al., GINI Study Group, LISA Study Group : Atopic diseases, allergic sensitization and exposure to traffic-related air pollution in children : Am J Respir Crit Care Med 2008, Jun 15, 177 (12) : 1331-7.

34. S.T.Holgate: Asthma and allergy - disorders of civilization? : Review QJM 1998, 91 : 171-184

35. Riediker M, Monn C, Koller T, Stahel W, Wüthrich B: Air pollutants enhance rhino conjunctivitis symptoms in pollen-allergic individuals: Ann Allergy Asthma Immunol. 2001, 87: 311-318.

36. Robert Taylor : For Urban Allergy Sufferers, Genes Make Matters Worse : Jan 23, 2004, Genome new network

37. Ousler GW, Wilcox KA, Gupta G, Abelson MB: An evaluation of the ocular drying effects of 2 systemic antihistamines: loratadine and cetirizine hydrochloride: Ann Allergy Asthma Immunol 2004, 93: 460-464.

\section{AUTHORS:}

1. Purvi Raj Bhagat

2. Rupal B Bhatt

3. Raj G Bhagat

4. Kalyani Deshpande

\section{PARTICULARS OF CONTRIBUTORS:}

1. Associate Professor, Department of Ophthalmology, M \& J Western Regional Institute of Ophthalmology, Civil Hospital, Ahmedabad, Gujarat.

2. Assistant Professor, Department of Ophthalmology, $M$ \& J Western Regional Institute of Ophthalmology, Civil Hospital, Ahmedabad, Gujarat.

3. Associate Professor, Department of Allergy, Dr. Bhagat's Allergy Asthma \& Respiratory Care Centre, Paldi, Ahmedabad, Gujarat.
4. Resident, M \& J Western Regional Institute of Ophthalmology, Civil Hospital, Ahmedabad, Gujarat.

\section{NAME ADDRESS EMAIL ID OF THE CORRESPONDING AUTHOR:}

Dr. Purvi Raj Bhagat, A 301, Chandanbala, Opp. Suvidha Shopping Centre, Paldi, Ahmedabad - 380007, Gujarat. Email-dr.purvibhagat@yahoo.com

Date of Submission: 29/08/2013.

Date of Peer Review: 31/08/2013.

Date of Acceptance: 13/09/2013.

Date of Publishing: 20/09/2013 